\title{
High Performance DGS Integrated Compact Antenna for 2.4/5.2/5.8 GHz WLAN Band
}

\author{
Mrinmoy CHAKRABORTY ${ }^{1}$, Srijita CHAKRABORTY ${ }^{2}$, P. Soni REDDY ${ }^{3}$, Susamay SAMANTA ${ }^{4}$ \\ ${ }^{1}$ Dept. of ECE, Dr. B. C. Roy Engineering College, Durgapur- 713206, West Bengal, India \\ ${ }^{2}$ Dept. of ECE, Institute of Engineering \& Management, Kolkata- 700091, West Bengal, India \\ ${ }^{3}$ Dept. of ECE, Kalyani Government Engineering College, Kalyani- 741235, West Bengal, India \\ ${ }^{4}$ Dept. of ETCE, Dr. B. C. Roy Polytechnic, Durgapur- 713206, West Bengal, India
}

mcbcrecbit@ rediffmail.com, mcbcrecbit@gmail.com, p.sonireddy@gmail.com, samantasusamay@gmail.com

Submitted April 17, 2016 / Accepted November 29, 2016

\begin{abstract}
An application specific tri-band hexagonal microstrip antenna with saw tooth shaped defected ground structure (DGS) is proposed. In this paper, a hexagonal microstrip antenna is designed for $5.2 \mathrm{GHz}$ which is basically WLAN band (5.15-5.35 GHz). Now in this structure two defects are suitably incorporated and the positions are so optimized that two additional frequency bands $2.4 \mathrm{GHz}$, i.e. the Bluetooth band $(2.4-2.48 \mathrm{GHz})$ and $5.8 \mathrm{GHz}$, i.e. the second WLAN band (5.725-5.825 GHz) are obtained. The fabricated prototype of the proposed antenna occupies an area $35 \mathrm{~mm} \times 27.4 \mathrm{~mm}$. Therefore, the structure has the characteristics of application specific multi band resonance. The variation of different parameters of the microstrip antenna is extensively studied. The proposed multiband microstrip antenna is functional simultaneously at three specific application band frequencies with approximately $84 \%$ surface area reduction for the largest patch dimension corresponding to $2.4 \mathrm{GHz}$.
\end{abstract}

\section{Keywords}

Microstrip antenna, hexagonal patch, defected ground structure, compact antenna, tri band antenna

\section{Introduction}

With the increasing demands of integrating several communication standards in a single compact system the designing of microstrip antenna, one of the vital microwave components, with three or more operating frequencies is becoming very popular. The ISM bands $2.4,5.2$ and $5.8 \mathrm{GHz}$ are widely used not only in the wireless local area networks but also for several wireless devices such as wireless printers, Bluetooth operated gadgets etc. The devices to be operated in these bands require multiband capability to comply with IEEE 802.11, 802.11a, 802.11b, 802.11g standards. Considering such ever increasing demands researchers have made several attempts to design compact microstrip antennas with high percentage of miniaturization for which different tech- niques, such as cutting regular shaped slits, slots, defected ground structure etc, are used to achieve the desired compactness [1-4]. A perturbation effect in the microstrip antenna is observed due to these techniques for which the antenna can be operated at a lower application frequency band. Efforts are also made to design multiband microstrip antennas which are resonant at more than one application frequency bands simultaneously [5-10]. For example, L-shaped slot, rectangular slot and defected ground plane coupled patch antennas were proposed to achieve multiband characteristics [5]. Design for dual-frequency antennas was proposed [8], consisting of two radiating elements arranged in a stacked structure. A small and low-profile microstrip-fed monopole antenna for triplefrequency operation is proposed where the radiating element was modified by loading it with protrudent strips and feeding it with a cross-shaped stripline [9]. Although the above antennas have many advantages, there are still some performances to be improved. These antenna designs may increase cost or complexity for practical design implementation in [6] and [11], or the overall dimensions of antenna are large as in [2] and [11], [12] thus limiting their integration with the future wireless communication systems.

In the proposed paper, a compact tri-band hexagonal microstrip antenna is designed which is initially resonating at $5.2 \mathrm{GHz}$ i.e. WLAN band. Then by the introduction of two saw tooth shaped defected ground structures, the hexagonal microstrip antenna is made to resonate simultaneously at 2.4 GHz i.e. the Bluetooth band and $5.8 \mathrm{GHz}$ i.e. the second WLAN band, along with $5.2 \mathrm{GHz}$ i.e. the first WLAN band. Thus, a compact hexagonal microstrip antenna with tri-band characteristics is achieved.

\section{Design Principles}

The dimension of the proposed microstrip hexagonal antenna is shown in Fig. 1. The antenna is printed on FR4 substrate of area $35 \mathrm{~mm} \times 27.4 \mathrm{~mm}$, thickness $0.8 \mathrm{~mm}$ with dielectric constant $\left(\epsilon_{r}\right) 4.4$ and dielectric 


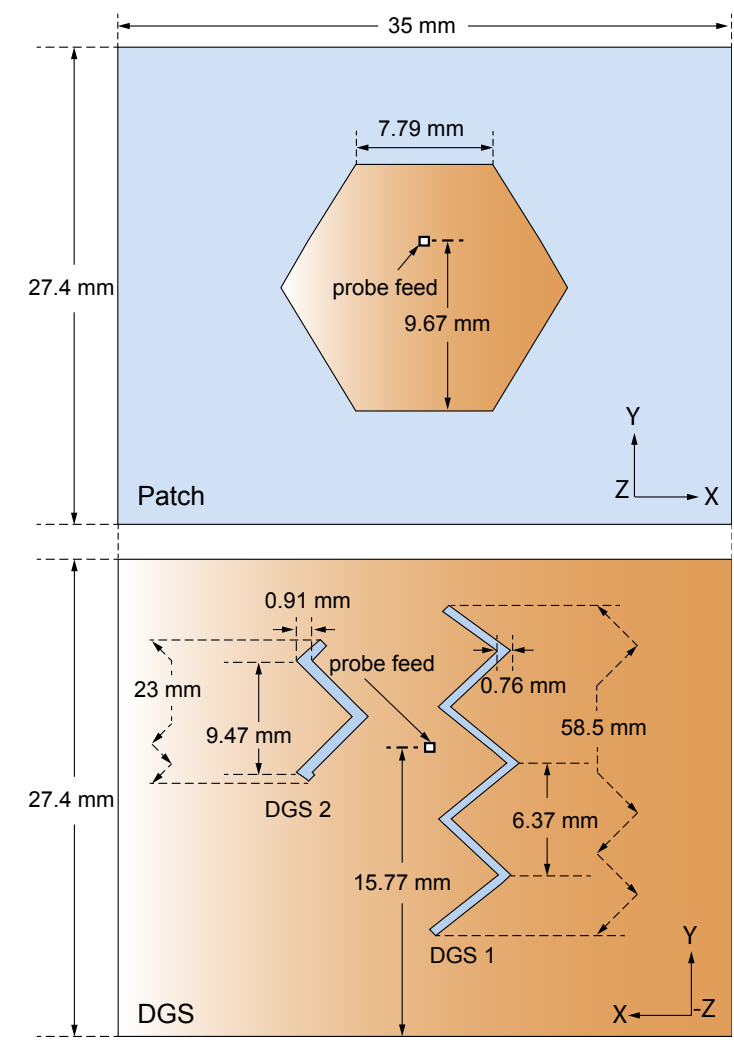

Fig. 1. Antenna layout with dimensions.

loss tangent $(\tan \delta)$ 0.002. Zeland IE3D software tool is used to simulate the proposed tri-band microstrip antenna.

Originally, the hexagonal microstrip antenna was designed to resonate at the WLAN band i.e. at $5.2 \mathrm{GHz}(5.15$ to $5.35 \mathrm{GHz}$ ). The resonance frequency formula of the hexagonal microstrip antenna was derived from the resonance frequency formula of the circular microstrip patch antenna by equating the respective areas [11]. The resonance frequency of the hexagonal microstrip antenna is given by

$$
f_{r}=\frac{\chi_{m n} c}{5.7138 s \sqrt{\epsilon_{r \mathrm{eff}}}}
$$

where $\chi_{m n}=\chi_{11}\left(\right.$ for $T M_{11}$ mode $)=1.84118$ and $\epsilon_{r \text { eff }}$ is the effective dielectric constant of the substrate material.

The antenna is fed by a coaxial probe and the optimum position of the feed is determined using [13]. Then two saw tooth shaped defects are incorporated into the ground plane of the proposed microstrip antenna. The length of the defected ground structures (DGS) is taken to be $\lambda_{0} / 2$, where $\lambda_{0}$ is the free space wavelength at 2.4 and $5.8 \mathrm{GHz}$, respectively. The DGS are so positioned that the mutual coupling between the two defects is minimum. Saw tooth shaped DGS structures are used for achieving greater degree of miniaturization in the radiating patch surface area compared to straight slot lines in the same antenna configuration.

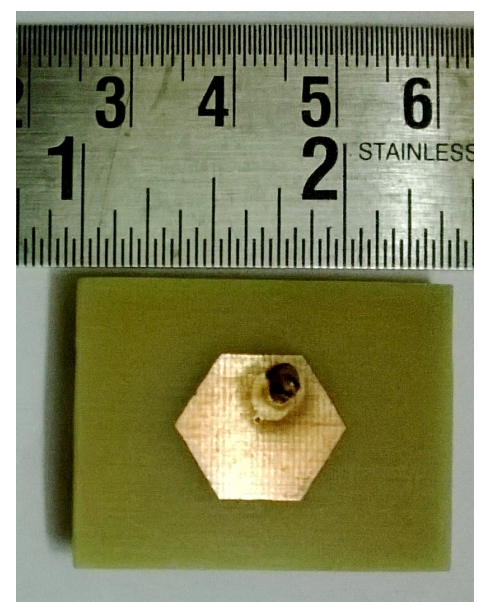

(a) Patch Plane.
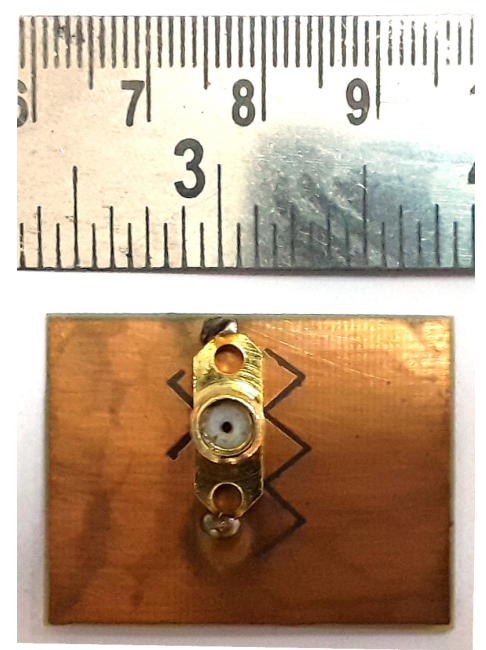

(b) Ground Plane with DGS.

Fig. 2. Snapshots of the fabricated antenna.

It can be observed that with the integration of the DGS structures the hexagonal microstrip antenna is resonant at $2.4 \mathrm{GHz}$ i.e. the Bluetooth band $(2.4-2.48 \mathrm{GHz})$ and $5.8 \mathrm{GHz}$ i.e. the second WLAN band $(5.725-5.825 \mathrm{GHz})$, along with $5.2 \mathrm{GHz}$ i.e. the first WLAN band $(5.15$ to $5.35 \mathrm{GHz}$ ). Thus, addition of DGS structures leads to antenna miniaturization and multiple resonances.

The final dimensions of the proposed antenna are shown in Fig. 1. The snapshots of the fabricated antenna are shown in Figures 2(a) and 2(b).

\section{Results and Discussion}

Figure 3 demonstrates both the simulated (with and without DGS) and measured $S_{11}$ versus frequency plots of the proposed hexagonal microstrip antenna. It can be observed that the hexagonal microstrip antenna is found to be resonant simultaneously at $2.4 \mathrm{GHz}$ (i.e. Bluetooth band) and $5.8 \mathrm{GHz}$ (i.e. second WLAN band), along with $5.2 \mathrm{GHz}$ (i.e. first WLAN band). The Bluetooth application band i.e. $2.4 \mathrm{GHz}$ and the second WLAN Band i.e. $5.8 \mathrm{GHz}$ are 


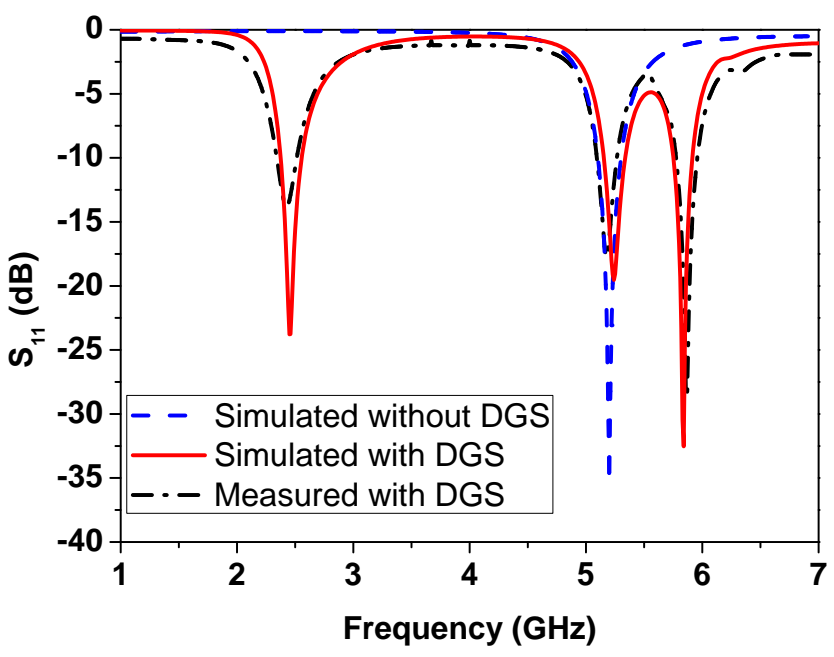

Fig. 3. $S_{11}$ vs. frequency plot.

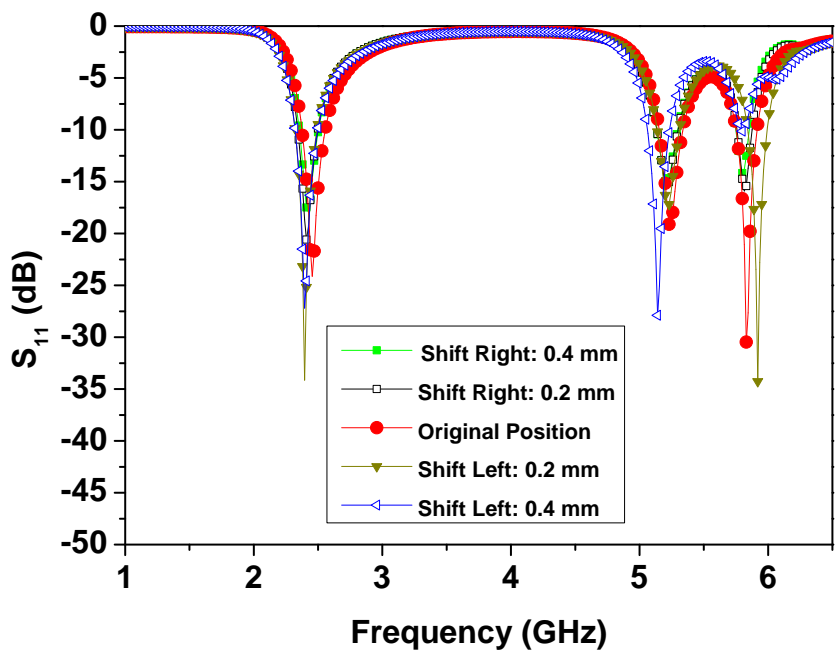

(a)

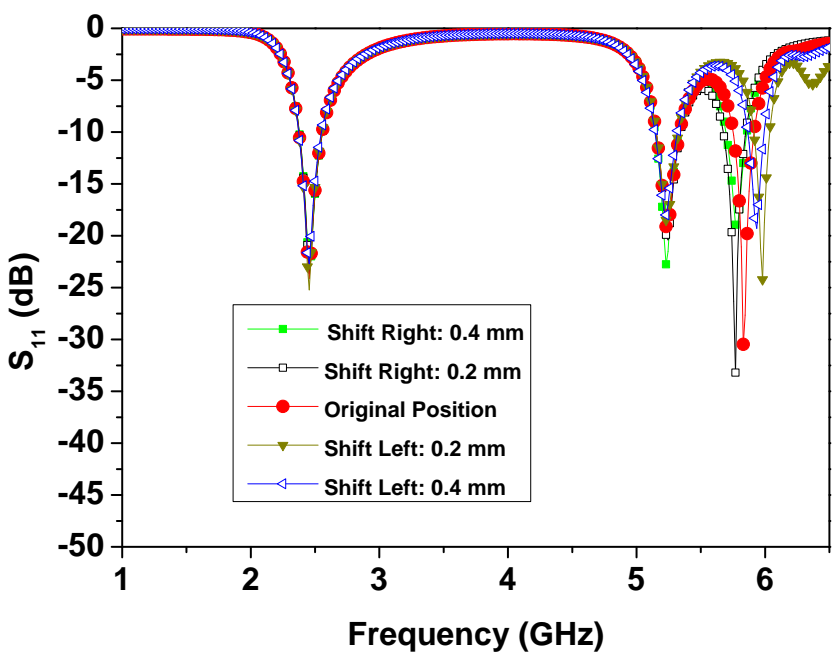

(b)

Fig. 4. Parametric variation of position of (a) DGS1 for $2.4 \mathrm{GHz}$, (b) DGS2 for $5.8 \mathrm{GHz}$.

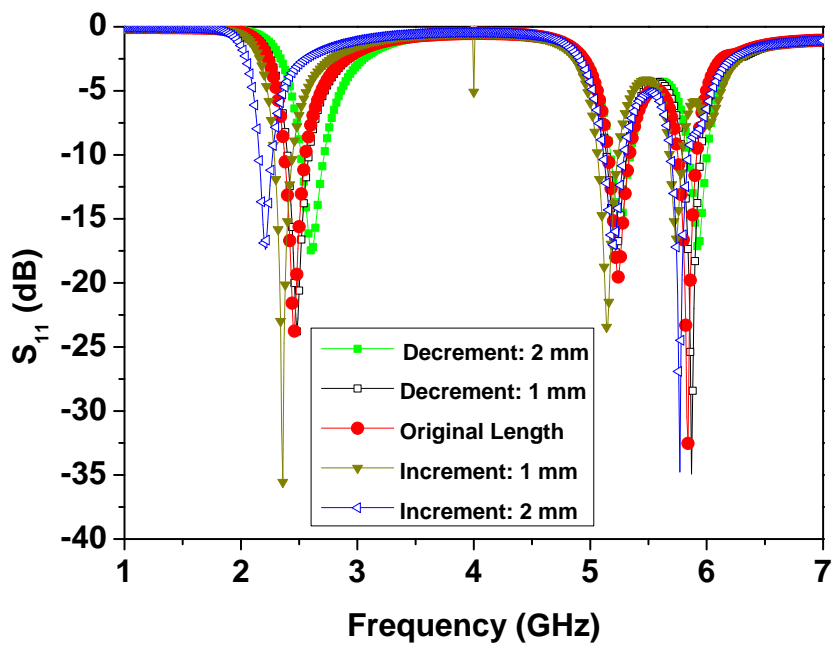

(a)

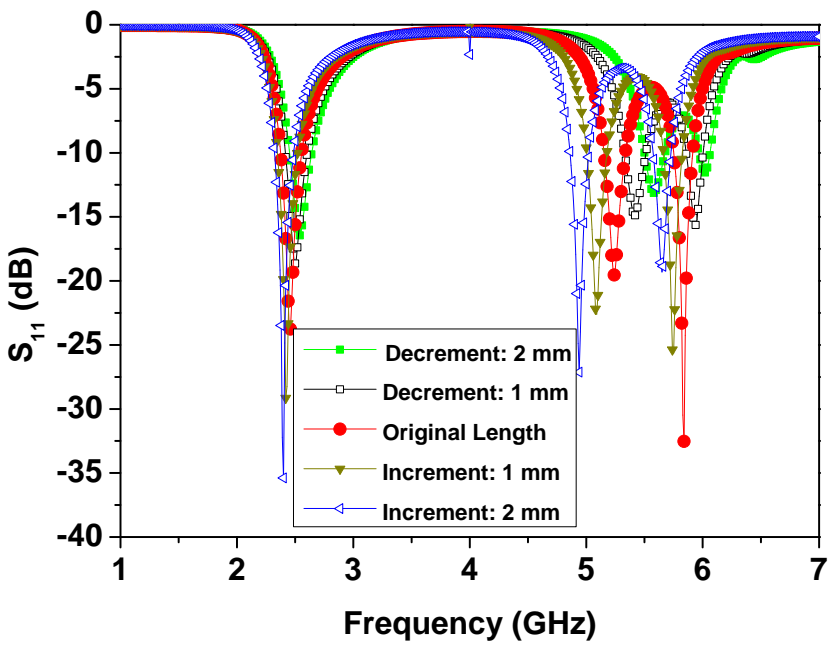

(b)

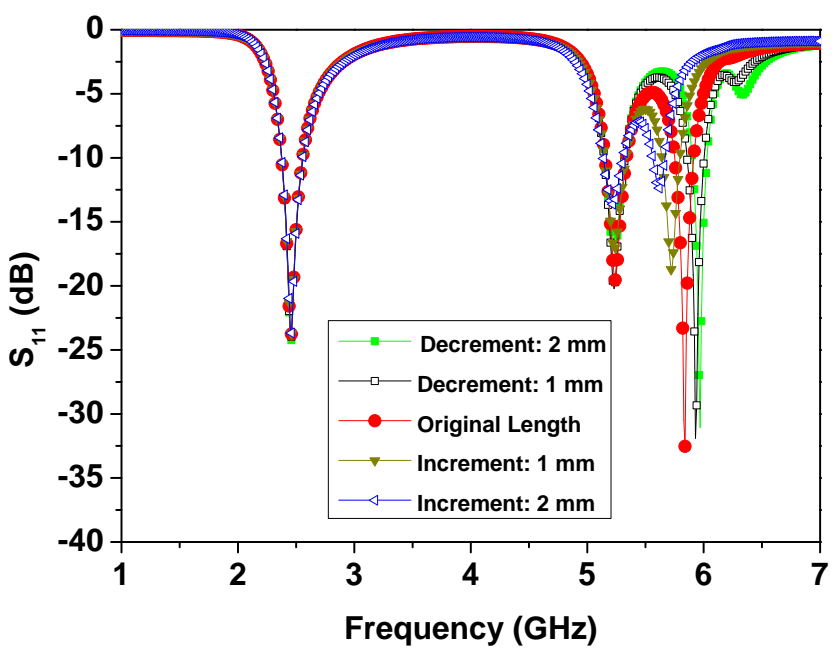

(c)

Fig. 5. Parametric variation of (a) length of DGS 1 for $2.4 \mathrm{GHz}$, (b) length of the hexagonal patch for $5.2 \mathrm{GHz}$, (c) length of DGS 2 for $5.8 \mathrm{GHz}$. 


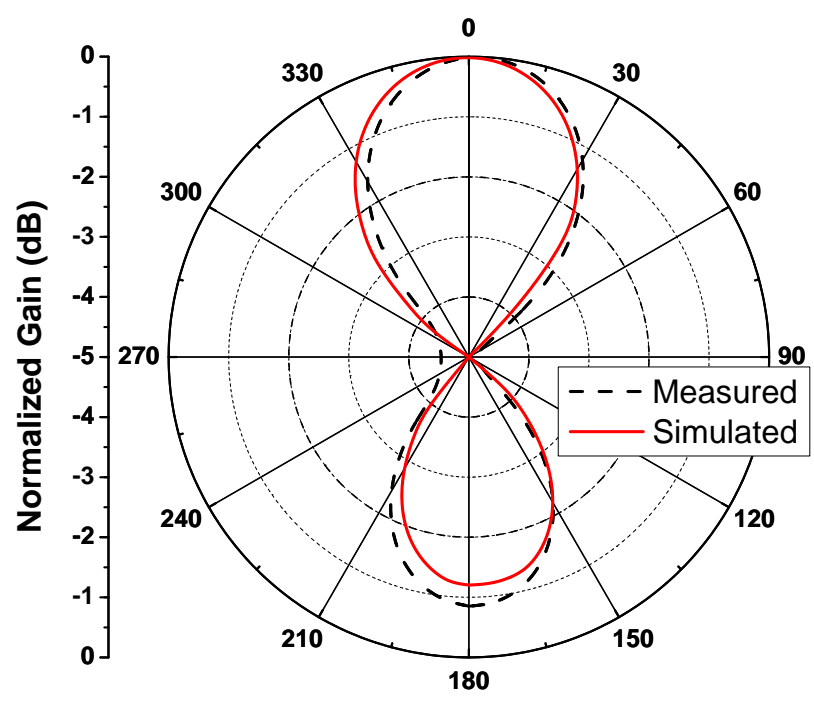

(a)

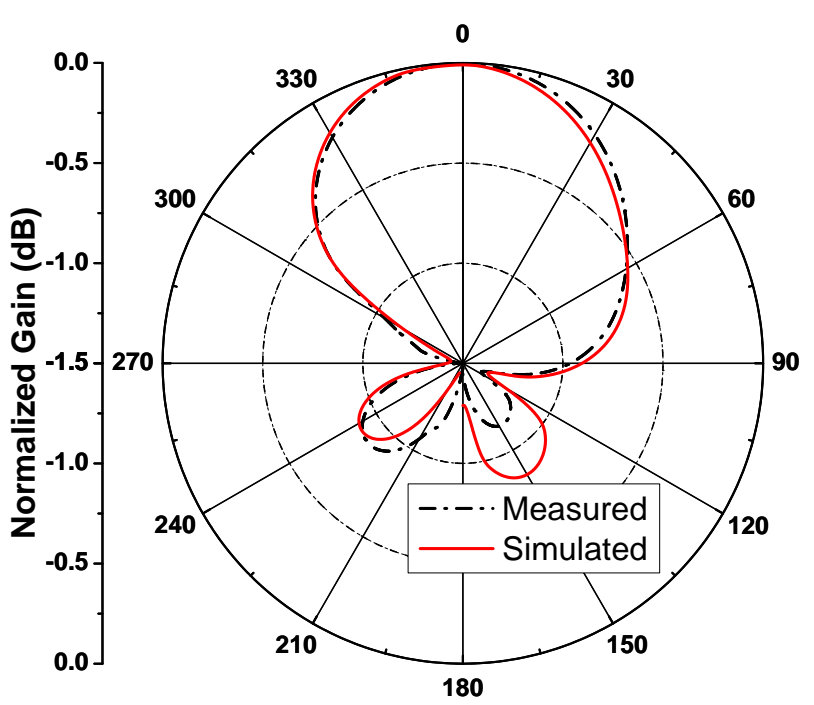

(b)

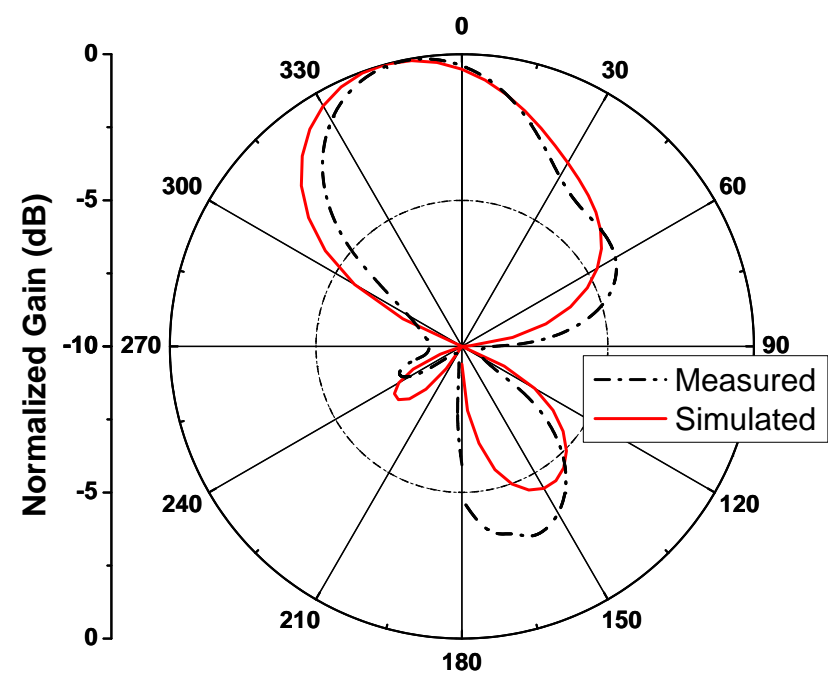

(c)

Fig. 6. Normalized E-plane radiation patterns for (a) $2.4 \mathrm{GHz}$, (b) $5.2 \mathrm{GHz}$, (c) $5.8 \mathrm{GHz}$.

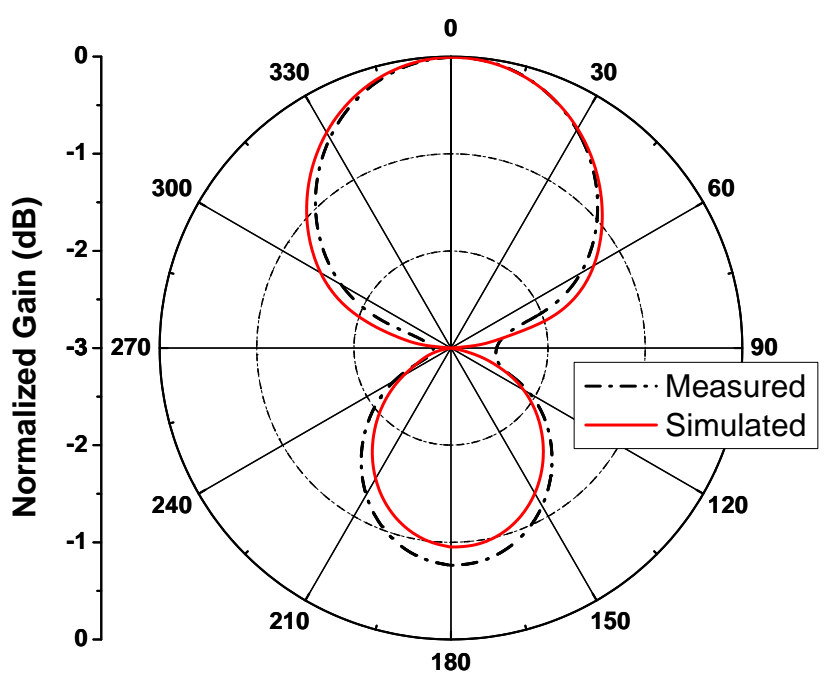

(a)

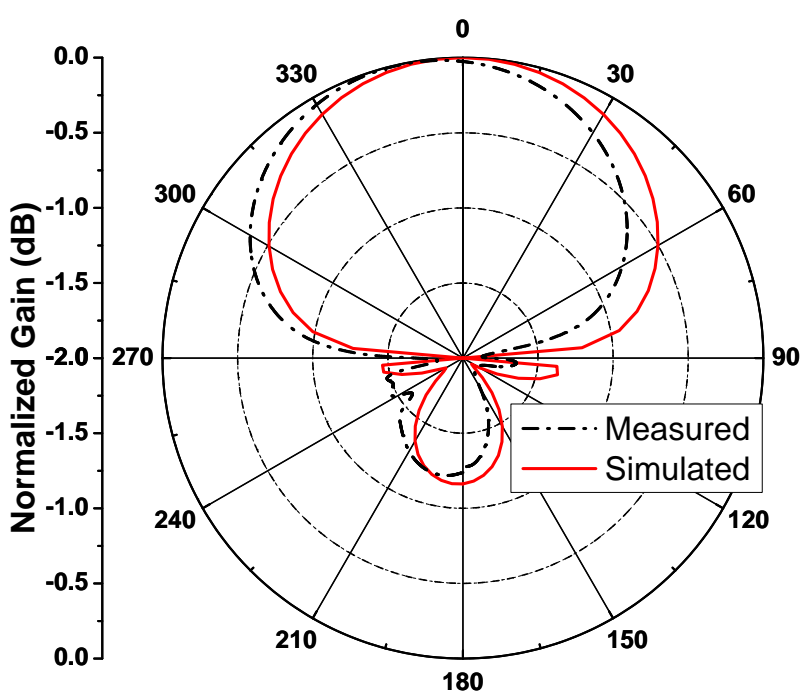

(b)

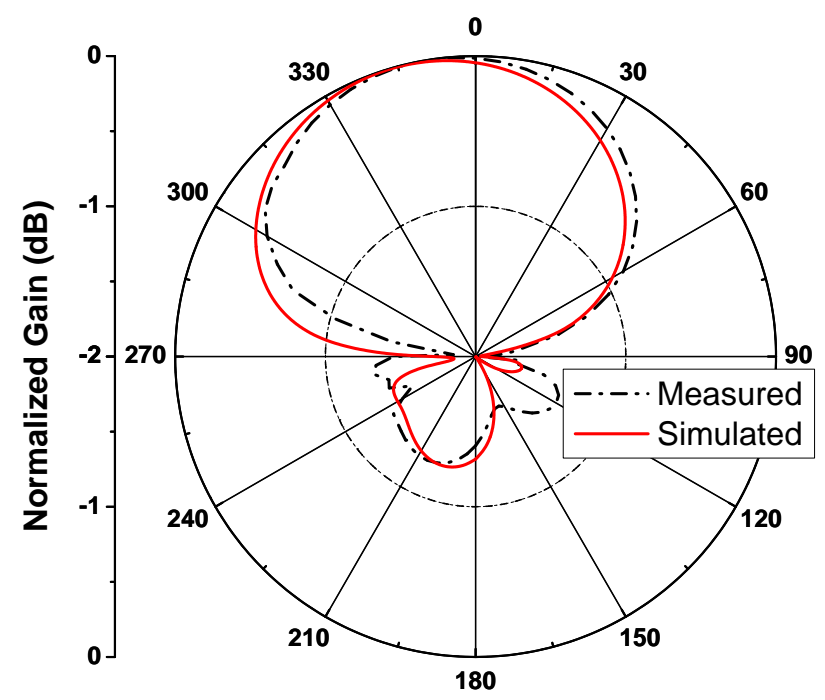

(c)

Fig. 7. Normalized H-plane radiation patterns for (a) $2.4 \mathrm{GHz}$, (b) $5.2 \mathrm{GHz}$, (c) $5.8 \mathrm{GHz}$. 


\begin{tabular}{|c|c|c|c|c|}
\hline Compared Antenna Structures & Frequency $(\mathbf{G H z})$ & Antenna Size $\left.\mathbf{( m m}^{2}\right)$ & \% Miniaturization & Gain $(\mathbf{d B i})$ \\
\hline$[2]$ & $0.93,1.8,2.45,5.2$ & $38 \times 43$ & 80 & $4.5-7.5$ \\
\hline$[6]$ & $2.5,3.5,5.2,5.8$ & $25 \times 38$ & Not Mentioned & $2.36-3.62$ \\
\hline$[1]$ & $1.575,3.71,5.9$ & $75 \times 75$ & 75 & $5.5,8$ and 9 \\
\hline$[12]$ & $2.45,3.5,5.28$ & $28 \times 40$ & Not Mentioned & $4.72,6.2$ and 3.8 \\
\hline Proposed Antenna & $2.4,5.2,5.8$ & $27.4 \times 35$ & 84 & $2.02,5.9$ and 4.14 \\
\hline
\end{tabular}

Tab. 1. Comparison of performance of the proposed antenna with some existing compact multiband antenna designs.

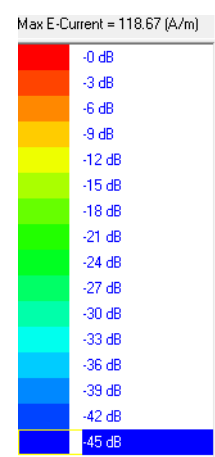

Freq: $2.4 \mathrm{GHz}$

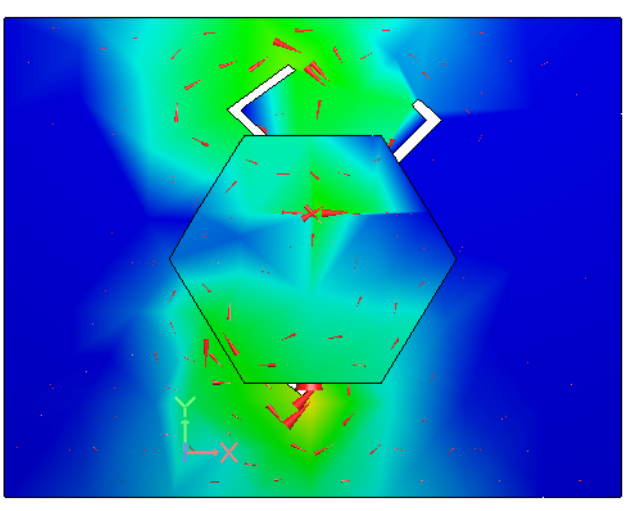

(a)

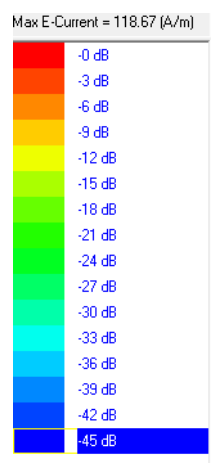

Freq: $5.2 \mathrm{GHz}$

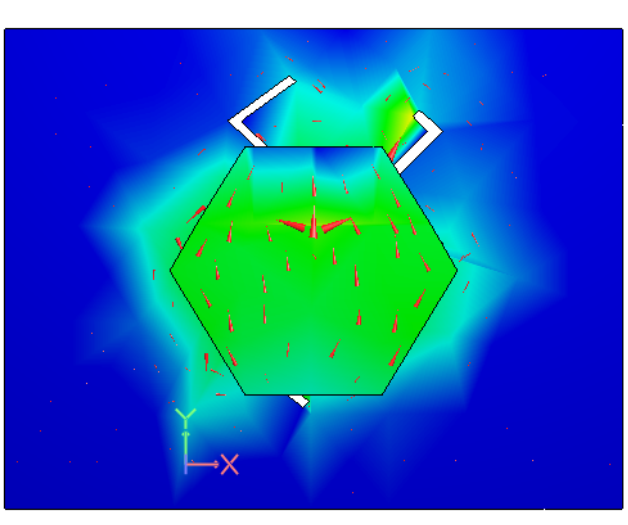

(b)
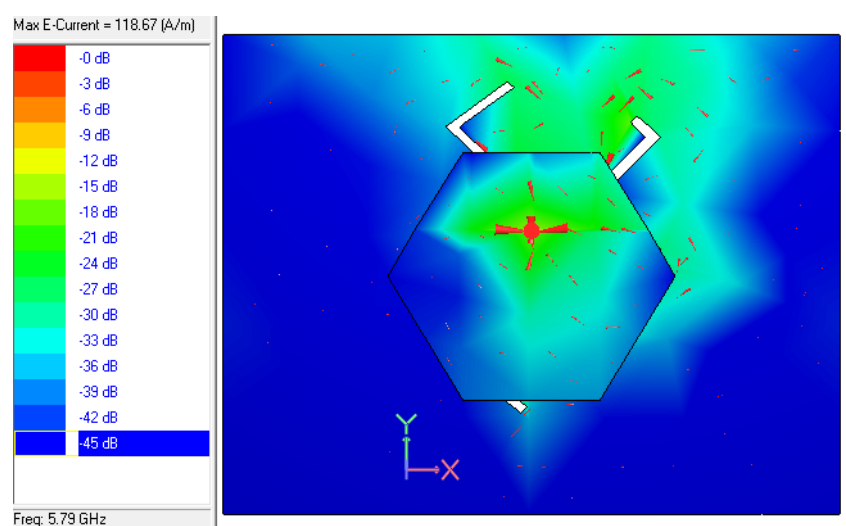

(c)

Fig. 8. Surface current distribution on the patch (a) $2.4 \mathrm{GHz}$, (b) $5.2 \mathrm{GHz}$, (c) $5.8 \mathrm{GHz}$.
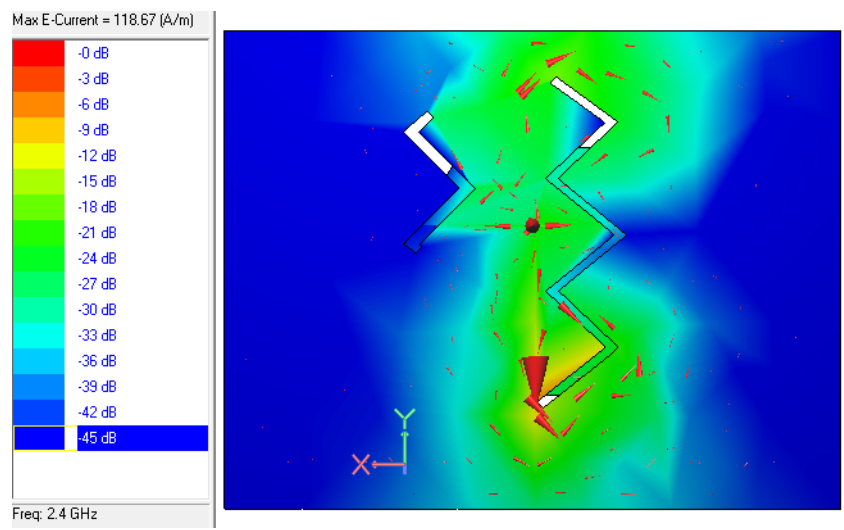

(a)

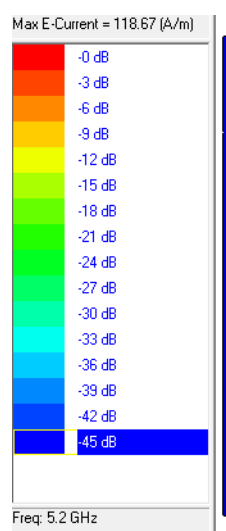

Freq: $5.2 \mathrm{GHz}$

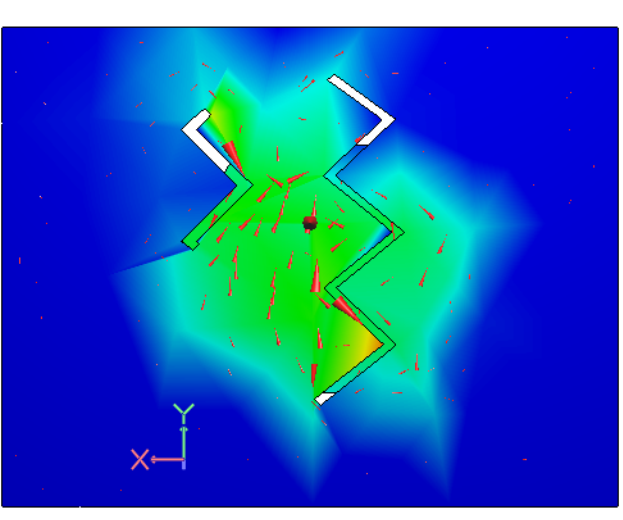

(b)

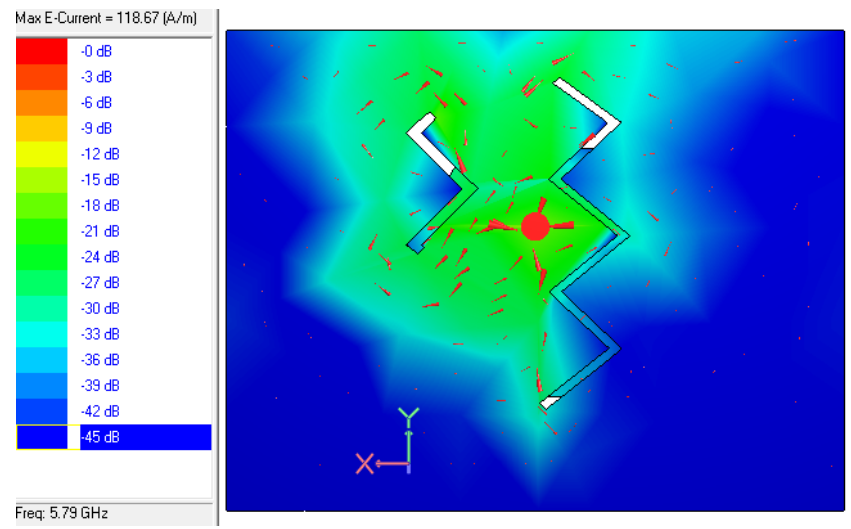

(c)

Fig. 9. Surface current distribution on the ground plane (a) $2.4 \mathrm{GHz}$, (b) $5.2 \mathrm{GHz}$, (c) $5.8 \mathrm{GHz}$. 
achieved by fine tuning the length of the DGS 1 and DGS 2 respectively, as shown in Fig. 1. It is seen that DGS1 and DGS2 behave as half-wavelength resonators at $2.4 \mathrm{GHz}$ and $5.8 \mathrm{GHz}$, respectively.

The parametric variations for each of the bands (2.4 GHz band due to the length and position of DGS 1, $5.2 \mathrm{GHz}$ band due to length of the hexagonal patch and $5.8 \mathrm{GHz}$ band due to the length and position of DGS 2) are shown in Figures 4(a)-4(b) and Figures 5(a)-5(c). The parametric variations for each of the frequency bands due to the position of the DGS structures on either side of the coaxial feed are illustrated in Figures 4(a)-4(b). It is observed that on varying the position of DGS 1 leftwards the resonant frequency band $2.4 \mathrm{GHz}$ shifts towards the lower frequency range. Likewise, changing the position of DGS 1 rightwards, the resonant frequency band $2.4 \mathrm{GHz}$ drifts towards the higher frequency range. In both the cases, the first WLAN band $5.2 \mathrm{GHz}$ and the second WLAN band $5.8 \mathrm{GHz}$ remains unchanged with the shift in position of DGS 1 . On varying the position of DGS 2 leftwards it is observed that the resonant frequency band $5.8 \mathrm{GHz}$ drifts towards the higher frequency range. Similarly, on varying the position of DGS 2 rightwards, the resonant frequency of $5.8 \mathrm{GHz}$ exhibits a tendency to drift towards the lower frequency range. In both the cases, the Bluetooth band of $2.4 \mathrm{GHz}$ and first WLAN band of $5.2 \mathrm{GHz}$ remains unaffected with the shift in position of DGS 2 .

From the parametric study illustrated in Figures 5(a) and 5(c), it is observed that as the length of DGS 1 and DGS 2 is increased, the resonant frequency shifts towards the lower frequency range and as the length of DGS 1 and DGS 2 is decreased, it shifts towards the higher frequency range. Thus, greater degree of antenna miniaturization can be achieved by increasing the length of the DGS structures keeping all other antenna parameters constant. Also, using saw tooth shaped DGS structures the overall radiating surface area of the patch is reduced by $84 \%$ compared to that of a hexagonal patch antenna resonating at $2.4 \mathrm{GHz}$ designed on the same substrate but without any DGS incorporated into its ground plane.

The parametric variation for the frequency band $5.2 \mathrm{GHz}$ with length of the hexagonal patch is displayed in Fig. 5(b). It can be observed that the variations in the length of the hexagonal radiator has significant effect on the middle resonant frequency band at $5.2 \mathrm{GHz}$, minor effect on the higher resonant frequency band at $5.8 \mathrm{GHz}$ and negligible effect on the lower resonant frequency band at $2.4 \mathrm{GHz}$. As the length of the hexagonal radiator is increased the resonant frequency shifts towards the lower frequency range.

It is also found from Figures 4(a)-4(b) and Figures 5(a)-5(c) that each parametric variation is having contribution in one of the resonating frequency bands without any significant variation in the other frequency bands. Addition of the two saw tooth shaped DGS structures has negligible effect on the resonant frequency band $5.2 \mathrm{GHz}$ of the original hexagonal patch antenna. Variations in the length and position of DGS structures results in significant variations in the two additional frequency bands $2.4 \mathrm{GHz}$ and $5.8 \mathrm{GHz}$ for DGS 1 and DGS 2, respectively.

From the theory of microstrip antenna it is known that the radiation pattern is normal to the surface of the patch. Thus, the normalized radiation patterns for $\phi=0^{\circ}$ and $\phi=90^{\circ}$ are as shown in Figures 6(a)-6(c) and Figures $7(\mathrm{a})-7(\mathrm{c})$, respectively. It is observed that the proposed antenna shows nearly bidirectional patterns both in the E-plane and the H-plane at three desired operating frequencies. The gain values are about $2.02 \mathrm{dBi}$ at $2.4 \mathrm{GHz}, 5.9 \mathrm{dBi}$ at $5.2 \mathrm{GHz}$ and $4.14 \mathrm{dBi}$ at $5.8 \mathrm{GHz}$.

The comparative study of the performance characteristics of the proposed antenna with different existing compact multiband antenna designs [2], [6], [11], [12] is summarized in Tab. 1. It is observed that the proposed antenna achieves greater miniaturization compared to other existing structures with considerably small overall antenna size and acceptable gain.

\section{Observation of Current Distribu- tion}

The operation mechanism of the proposed multiband can be explained with the help of simulated current distribution as shown in Fig. 8 and Fig. 9. Figures 8(a) and 9(a) together show that for the lowest frequency band $(2.4 \mathrm{GHz})$ the current vectors are essentially concentrated along DGS 1 and the patch. Again it can be observed from Fig. 8(b) and Fig. 9(b) that for the middle frequency band $(5.2 \mathrm{GHz})$ a large number of current vectors is concentrated on the radiator. Figures 8(c) and 9(c). 8(c) portray that for the highest frequency band $(5.8 \mathrm{GHz})$ the current vectors are essentially concentrated along DGS 2 and the patch.

\section{Conclusion}

In this paper, a tri-band antenna has been proposed, prototyped and analyzed. The multiband operation of the proposed antenna is achieved using two saw tooth shaped defects in the ground plane of the hexagonal patch antenna. The primary reason for making the DGS slots saw tooth shaped is to accommodate the resonator length of $58.5 \mathrm{~mm}$ for $2.4 \mathrm{GHz}$ within the ground plane area of $35 \mathrm{~mm} \times 27.4 \mathrm{~mm}$. The antenna shows satisfactory radiation performance with acceptable gain over each of the desired frequency bands and appreciable antenna surface area miniaturization of $84 \%$ for the largest resonating length corresponding to the lowest resonating frequency $2.4 \mathrm{GHz}$. Therefore, it is a good candidate for the proposed multiband application.

\section{Acknowledgments}

The authors would like to appreciate the support of BIT, Mesra, Ranchi, Jharkhand, India, Dr. B. C. Roy Engineer- 
ing College, Durgapur, West Bengal, India and are in debt to all concerned.

\section{References}

[1] LI, Y., Z. ZHANG, J., ZHENG, J. F., et al. Compact heptaband reconfigurable loop antenna for mobile handset. IEEE Antennas and Wireless Propagation Letters, 2011, vol. 10, p. 1162-1165. DOI: 10.1109/LAWP.2011.2171311

[2] ELSHEAKH, D. M., ABDALlAH, E. A. Compact multiband multifolded-slot antenna loaded with printed-IFA. IEEE Antennas and Wireless Propagation Letters, 2012, vol. 11, p. 1478-1481. DOI: $10.1109 /$ LAWP.2012.2232273

[3] ZHAI, H. Q., MA, Z. H., HAN, Y., et al. A compact printed antenna for triple-band WLAN/WiMAX applications. IEEE Antennas and Wireless Propagation Letters, 2013, vol. 12, p. 65-68. DOI: 10.1109/LAWP.2013.2238881

[4] MOOSAZADEH, M., KHARKOVSKY, S. Compact and small planar monopole antenna with symmetrical L- and U-shaped slots for WLAN/WiMAX applications. IEEE Antennas and Wireless Propagation Letters, 2014, vol. 13, p. 388-391. DOI: 10.1109/LAWP.2014.2306962

[5] CHEN, S., FANG, M., DONG, D., et al. Compact multiband antenna for GPS/WiMAX/WLAN applications. Microwave and $O p$ tical Technology Letters, 2015, vol. 57, no. 8, p. 1769-1773. DOI: $10.1002 / \mathrm{mop} .28465$

[6] LIU, W. X., YIN, Y. Z., XU, W. L. Compact self-similar tripleband antenna for WLAN/WiMAX applications. Microwave and Optical Technology Letters, 2012, vol. 54, no. 4, p. 1048-1087. DOI: $10.1002 /$ mop.26732

[7] LI, R., PAN, B., LASKAR, J., et al. A compact broadband planar antenna for GPS, DCS-1800, IMT-2000, and WLAN applications. IEEE Antennas and Wireless Propagation Letters, 2007, vol. 6, p. 25-27. DOI: 10.1109/LAWP.2006.890754

[8] MA, S. L., ROW, J. S. Design of single-feed dual-frequency patch antenna for GPS and WLAN applications. IEEE Transactions on Antennas and Propagation, 2011, vol. 59, no. 9, p. 3433-3436. DOI: 10.1109/TAP.2011.2161453

[9] LIU, W. C., WU, C. M., DAI, Y. Design of triple-frequency microstrip-fed monopole antenna using defected ground structure. IEEE Transactions on Antennas and Propagation, 2011, vol. 59 no. 7, p. 2457-2463. DOI: 10.1109/TAP.2011.2152315

[10] ZHANG, T., LI, R., JIN, G., et al. A novel multiband planar antenna for GSM/UMTS/LTE/Zigbee/RFID mobile devices. IEEE Transactions on Antennas and Propagation, 2011, vol. 59, no. 11, p. 42094214. DOI: 10.1109/TAP.2011.2164201

[11] MONDAL, T., SAMANTA, S., GHATAK, R., et al. A novel triband hexagonal microstrip patch antenna using modified Sierpinski fractal for vehicular communication. Progress In Electromagnetics Research C, 2015, vol. 57, p. 25-34. DOI: 10.2528/PIERC15021105
[12] REDDY, B. R. S., VAKULA, D. Compact zigzag-shaped-slit microstrip antenna with circular defected ground structure for wireless applications. IEEE Antennas and Wireless Propagation Letters, 2015. vol. 14, p. 678-681. DOI: 10.1109/LAWP.2014.2376984

[13] BALANIS, C. A. Antenna Theory: Analysis and Design. Hoboken, NJ (USA): John Wiley \& Sons Inc., 2005.

\section{About the Authors...}

Mrinmoy CHAKRABORTY was born in the year 1977 in West Bengal, India. He received his M.Tech degree in Electronics and Communiction Engineering (Communiction) from Kalyani Govt. Engineering College, West Bengal, India in the year 2008. He is currently working toward his Ph.D. degree in the ECE department, BIT Mesra, Ranchi, India. At present, he is an Assistant Professor in the Electronics and Communication Engineering department, Dr. B. C. Roy Engineering College, Durgapur, West Bengal, India. His research interests include RF-Microwave Component, Smart Antennas and Meta Materials. He is a member of IEEE.

Srijita CHAKRABORTY was born in the year 1988 in West Bengal, India. She received her M.Tech degree in Electronics and Communiction Engineering (Communiction) from Kalyani Govt. Engineering College, West Bengal, India in the year 2013. At present, she is an Assistant Professor in the Electronics and Communication Engineering department, Institute of Engineering \& Management, Kolkata, West Bengal, India. Her research interests include Antennas for Wireless Communication.

P. Soni REDDY was born in the year 1987 in Andhra Pradhesh, India. She received her B.Tech degree in Electronics and Communiation Engineering from Academy of Technology, West Bengal, India in 2011. She is currently pursuing her M.Tech degree in Electronics and Communiction Engineering (Communiction) from Kalyani Govt. Engineering College, West Bengal, India. Her research interests include Microstrip Antenna and Dielectric Resonator Antenna for Wireless Communication.

Susamay SAMANTA was born in the year 1989 in West Bengal, India. He received his M.Tech degree in Electronics and Communiction Engineering (Communiction) from Dr. B. C. Roy Engineering College, Durgapur, West Bengal, India in the year 2015. At present, he is a Lecturer in the Electronics and Telecommunication Engineering department, Dr. B. C. Roy Polytechnic, Durgapur, West Bengal, India. His research interests include Fractal Microstrip and Dielectric Resonator Antenna for Wireless Communication. $\mathrm{He}$ is a member of IEEE. 